\title{
Analysis of risk factors for severe adverse effects of oral 5-fluorouracil S-1 in patients with advanced gastric cancer
}

\author{
Takeharu Yamanaka ${ }^{1}$, Shigemi Matsumoto ${ }^{2}$, Satoshi Teramuka $^{3,4}$, Ryota Ishiwata $^{4}$, Yoji Nagai $^{4}$, \\ and MASANORi FuKUSHIMA ${ }^{2,3,4}$ \\ ${ }^{1}$ Cancer Biostatics Laboratory, Institute for Clinical Research, National Kyushu Cancer Center, 3-1-1 Notame, Minami-ku, \\ Fukuoka 811-1395, Japan \\ ${ }^{2}$ Department of Translational Clinical Oncology, Graduate School of Medicine, Kyoto University, Kyoto, Japan \\ ${ }^{3}$ Department of Clinical Trial Design and Management, Graduate School of Medicine, Kyoto University, Kyoto, Japan \\ ${ }^{4}$ Translational Research Informatics Center, Kobe, Japan
}

\begin{abstract}
Background. S-1 is an oral fluoropyrimidine that promises better and accessible treatment. This article identifies the risk factors for severe adverse events of S-1 from nationwide survey data.

Methods. Advanced gastric cancer patients scheduled to receive S-1 monotherapy ( $80 \mathrm{mg} /$ day for days 1-28, every 6 weeks) were registered throughout Japan between 1999 and $2000(n=$ 3758). Univariate and multivariate analyses were performed to explore the risk factors for severe adverse events.

Results. A multivariate analysis revealed that grade 3 or 4 neutropenia was significantly associated with baseline renal function [odds ratios (ORs) corresponding to creatinine clearance $(\mathrm{ml} / \mathrm{min})$ ranges of $50-79,30-49$, and $<30$ in reference to $>80$ increased to $1.21,1.79$, and 2.43 , respectively], and the estimated incidence probability of grade 3 or 4 neutropenia ranged from $5.0 \%$ to $33.7 \%$ depending on the initial status of renal function and baseline neutrophil count. Some prior chemotherapeutic drug use may be implicated in the experience of adverse events; decreases in hemoglobin, nausea/vomiting, and hyperbilirubinemia were observed to be influenced by the previous use of irinotecan $(\mathrm{OR}=\mathbf{3 . 0 7}, P=\mathbf{0 . 0 0 3})$, mitomycin $(\mathrm{OR}=\mathbf{2 . 2 8}, P=0.004)$, and cisplatin $(\mathrm{OR}=1.60, P=0.007)$, respectively.

Conclusion. These findings identified possible risk factors for severe adverse events of $\mathrm{S}-1$ and the patient subgroups at potentially higher risk from its administration. The results will facilitate safer administration of $\mathrm{S}-1$ and thus promote enhanced tolerability and efficacy.
\end{abstract}

Key words S-1 · Gastric cancer · Adverse effects · Risk factors

\section{Introduction}

S-1 is a novel oral fluoropyrimidine consisting of tegafur and two biochemical modulators, gimeracil (CDHP)

Offprint requests to: $\mathrm{T}$. Yamanaka

Received: February 7, 2007 / Accepted: April 15, 2007 and oteracil potassium (Oxo), in a molar ratio of 1.0:0.4:1.0 [1]. The combination of CDHP with tegafur facilitates prolonged, higher 5-fluorouracil (5-FU) concentrations in blood and tumors. Oxo specifically inhibits the phosphoribosylation of 5-FU, leading to suppression of gastrointestinal toxicity [2]. In two phase II studies, S-1 exhibited high efficacy and tolerable safety in patients with previously untreated advanced gastric cancer (AGC). The pooled response rate, 1- and 2-year survival rates, and median survival time in the two studies (101 patients in total) were $45 \%, 37 \%, 17 \%$, and 8.1 months, respectively. Furthermore, grade 3 or 4 drug-related adverse reactions remained at low incidences of between $2 \%$ and $10 \%[3,4]$. In Japan, S-1 is currently being investigated as one of the key drugs for AGC, promising state-of-the-art treatment. It also offers the potential of broader use for other carcinomas, including colorectal, head and neck, lung, breast, and pancreatic cancers. The efficacy and safety of S-1 monotherapy demonstrated in the phase II studies of AGC were also reproducible for these carcinomas [5-10]. S-1 is thus considered likely to play a crucial role in the treatment of several advanced cancers.

The clinical use of S-1 in practice began with a postmarketing survey by the manufacturer in 1999 (Taiho Pharmaceuticals, Tokyo, Japan) [11]. The survey was prospectively conducted with the primary aim of collecting as wide a range of safety information as possible. Approximately 4000 patients were eventually enrolled, and the survey certainly promises to reveal comprehensive safety profile data on S-1. A previous article has already reported that the overall incidence of adverse drug reactions during the first two cycles in the survey were $74 \%$ for all grade events and $25 \%$ for grade 3 or 4 events; the tolerable safety of S-1 in the phase II studies was confirmed in a large population [11].

In this article, we use the data from the same survey and aim to identify risk factors associated with the oc- 
currence of grade 3 or 4 adverse events. Specifically, we focus on the events in the first two cycles. This is because most of the first occurrence of grade 3 or 4 events was observed during this period; more than $70 \%$ of hematological events were experienced during the first and second cycles, and the same holds true for most of the nonhematological events. Adverse events experienced during the early period have clinically important implications because they lead to a decline in patient compliance with the drug in subsequent treatment cycles. Thus, as for S-1, adverse events during the early period are of particular significance; thus, as in the previous article [11], we focus here on grade 3 or 4 events in the first two cycles.

\section{Methods}

\section{Patients}

From March 1999 through March 2000, all of patients scheduled for administration of S-1 were registered in the survey. It was prospectively conducted by the manufacturer to comply with the regulatory requirement for the collection of as much safety profile data as possible during the early postmarketing period of the drug. All the registered patients gave informed consent before enrollment and received S-1 as a single-agent therapy. Central registration and data collection and management were performed to ensure data quality [11].

\section{Treatment delivery}

The initial dosages of S-1 were assigned on the basis of body surface area (BSA), and the patients received one of the following oral dosages twice daily after meals: $40 \mathrm{mg}$ for patients with BSA $<1.25 \mathrm{~m}^{2}, 50 \mathrm{mg}$ for BSA $\geq 1.25$ and $<1.50 \mathrm{~m}^{2}$, and $60 \mathrm{mg}$ for BSA $\geq 1.50 \mathrm{~m}^{2}$. One cycle of the therapy comprised the administration of single agent S-1 for 28 consecutive days followed by 14 days of no treatment. This schedule was repeated every 6 weeks until the occurrence of disease progression, unacceptable toxicities, or patient refusal. Dose modification followed the schedule used in the previous studies $[3,4]$.

\section{Assessment of safety}

Adverse events were assessed and graded 1 to 4 according to the criteria of the Japan Society of Clinical Oncology, which is the National Cancer Institute Common Toxicity Criteria (NCI-CTC) version 1 [12] with a few minor modifications adapted to Japanese patients [13]. To confirm the results of laboratory tests and the occur- rence of adverse events, onsite monitoring visit was conducted once a week during the first cycle and twice a month thereafter.

\section{Statistical methods}

Statistical analysis for the association between clinical variables and severe adverse events was conducted as follows. For each adverse event, the univariate Fisher's exact test was used to screen out possible associated factors from available clinical variables. From these screened factors, a backward stepwise logistic regression method was then used to determine the risk factors [14]. All the variable selection procedures were based on a two-tailed statistical significance level of $5 \%$. All $P$ values were reported as two-tailed and calculated using SAS for Windows (SAS Institute, Cary, NC, USA).

\section{Results}

\section{Patient population}

A total of 4177 patients were registered from 757 institutions in Japan. Of these, 3758 were AGC patients and used for our analysis. The data from the other 419 patients were excluded owing to no administration of S-1 or malignancies other than AGC. The demographics of the patients are summarized in Table 1 . They closely resembled those of patients in the previous phase II studies $[3,4]$.

\section{Risk factors for grade 3 or 4 adverse events}

The initial candidate variables were age, sex, body mass index, performance status, liver metastasis, disease status (inoperable, recurrent, or residual), chemotherapy within the 6 months prior to starting S-1, baseline complications, and basic laboratory test parameters (hemoglobin, leukocyte count, neutrophil count, platelet count, total bilirubin, serum aspartate aminotransferase, serum alanine aminotransferase, and serum creatinine). Table 2 summarizes the risk factors, which were determined from among these variables, for some of the key adverse events of S-1: neutropenia, decrease in hemoglobin, nausea/vomiting, anorexia, and hyperbilirubinemia. Neutropenia was associated with creatinine clearance calculated using the Cockcroft and Gault equation [15]. For each range of creatinine clearance ( $\mathrm{ml} / \mathrm{min})(50-79,30-49$, and $<30)$, the odds ratios (ORs) in reference to the range $>80$ were estimated to be 1.21 $(P=0.238), 1.79(P=0.005)$, and $2.43(P=0.107)$, respectively (Table 2 ), where creatinine clearance was categorized according to previous reports $[16,17]$. It is 
Table 1. Patient demographics and characteristics $(n=3758)$

\begin{tabular}{|c|c|}
\hline Characteristics & \\
\hline \multicolumn{2}{|l|}{ Age (years) } \\
\hline Median (range) & $63(18-92)$ \\
\hline \multicolumn{2}{|l|}{ Sex } \\
\hline Male & $2624(70 \%)$ \\
\hline Female & $1134(30 \%)$ \\
\hline \multicolumn{2}{|c|}{ Body surface area $\left(\mathrm{m}^{2}\right)$} \\
\hline Median (range) & $1.47(1.03-2.04)$ \\
\hline \multicolumn{2}{|c|}{ Body mass index $\left(\mathrm{kg} / \mathrm{m}^{2}\right)$} \\
\hline Median (range) & $19.5(12.3-33.5)$ \\
\hline \multicolumn{2}{|c|}{ ECOG performance status } \\
\hline 0 & $2263(60 \%)$ \\
\hline 1 & $1207(32 \%)$ \\
\hline 2 & $270(7 \%)$ \\
\hline $3-4$ & $18(1 \%)$ \\
\hline \multicolumn{2}{|l|}{ Disease status } \\
\hline Inoperable & $1276(34 \%)$ \\
\hline Recurrent & $1605(43 \%)$ \\
\hline Residual & $877(23 \%)$ \\
\hline \multicolumn{2}{|l|}{ Liver metastasis $^{\mathrm{a}}$} \\
\hline Absent & $2711(73 \%)$ \\
\hline $\mathrm{H} 1$ & $270(7 \%)$ \\
\hline $\mathrm{H} 2$ & $195(5 \%)$ \\
\hline H3 & $532(14 \%)$ \\
\hline \multicolumn{2}{|c|}{ Creatinine clearance ${ }^{\mathrm{b}}(\mathrm{ml} / \mathrm{min})$} \\
\hline$\geq 80$ & $1379(37 \%)$ \\
\hline $50-79$ & $1811(48 \%)$ \\
\hline $30-49$ & $530(14 \%)$ \\
\hline$<30$ & $38(1 \%)$ \\
\hline \multicolumn{2}{|c|}{ Prior chemotherapy within 6 months } \\
\hline No & $1831(49 \%)$ \\
\hline Yes & 1927 (51\%) \\
\hline
\end{tabular}

ECOG, Eastern Cooperative Oncology Group

${ }^{\text {a }} \mathrm{H} 1$, unilateral lobe metastasis; $\mathrm{H} 2$, bilateral lobe metastasis with a few scattered foci; $\mathrm{H} 3$, bilateral lobe metastasis with numerous foci

${ }^{\mathrm{b}}$ Calculated by the Cockcroft and Gault equation

particularly important that the patients with an impaired baseline renal function of creatinine clearance $<30 \mathrm{ml} /$ min had a more than two-fold risk compared to normal patients, although this was not statistically significant due to small sample size in this category (38/3758 patients). Some severe adverse events, such as decrease in hemoglobin, nausea/vomiting, thrombocytopenia, anorexia, and fatigue, naturally depended on baseline symptoms (with baseline symptom versus no symptom: $\mathrm{OR}=5.05, P<0.001$ for hemoglobin decrease; $\mathrm{OR}=$ $3.59, P<0.001$ for nausea/vomiting; $\mathrm{OR}=3.62, P<0.001$ for anorexia; $\mathrm{OR}=7.85, P<0.001$ for thrombocytopenia; $\mathrm{OR}=5.70, P<0.001$ for fatigue). It was also found that treatment history with some anticancer agents may possibly have an effect on the appearance of adverse effects. Hemoglobin decrease, nausea/vomiting, and hyperbilirubinemia were founded to be affected by the previous use of irinotecan $(\mathrm{OR}=3.07, P=0.003)$, mitomycin $(\mathrm{OR}=2.28, P=0.004)$, and cisplatin $(\mathrm{OR}=1.60$, $P=0.007$ ) (Table 2). For other key gastrointestinal events including diarrhea and stomatitis, which are typical adverse effects associated with fluoropyrimidine, no risk factors were identified in our analysis at the 5\% level of significance. Thus, factors other than those considered here, possibly molecular ones, might be associated with the occurrence of severe diarrhea or stomatitis.

Table 3 shows the estimated incidence probabilities of severe neutropenia, nausea/vomiting, and hyperbilirubinemia, which can be obtained from the odds ratios in the logistic regression models in Table 2. It is observed that the incidence probability of neutropenia has a wide range, depending on the initial status of creatinine clearance and baseline neutrophil count. For patients with a normal condition (creatinine clearance $\geq 80 \mathrm{ml} / \mathrm{min}$ and neutrophil count $\geq 2000 / \mathrm{mm}^{3}$ ), the estimated incidence probability remains at $5.0 \%$; whereas it rises to $33.7 \%$ for patients with an impaired baseline condition of creatinine clearance $<30 \mathrm{ml} / \mathrm{min}$ and a neutrophil count $<2000 / \mathrm{mm}^{3}$. Similarly, the incidence probability of nausea/vomiting ranges from $1.5 \%$ to $47.8 \%$ depending on initial performance status, nausea/vomiting at baseline, and a history of mitomycin use. Hyperbilirubinemia ranges from $1.8 \%$ to $23.6 \%$ depending on initial status of liver metastasis, baseline platelet count, and a history of cisplatin use. The incidence probabilities of other adverse events can be estimated similarly.

\section{Discussion}

After approval was obtained in Japan, the clinical use of S-1 had been monitored for 1 year in a prospectively registered survey by the manufacturer. Since the survey was conducted in the context of medical practice, it included a certain number of patients who are generally excluded from premarketing clinical trials, such as those with peritoneal dissemination. For AGC, there is often no direct comparison of safety profiles between phase II studies and general use due primarily to the exclusion of such patients. The current survey was conducted as a census with the registration of all the patients treated with S-1; therefore, it should assist in bridging the gap, as it provides a comprehensive safety profile [11].

The purpose of this study was to describe the attempts to capture the potential risk factors for severe adverse events of S-1. Myelosuppression (neutropenia, hemoglobin decrease, or thrombocytopenia) was the dose-limiting toxicity in the phase I study [18] and recognized as one of the key adverse effects of S-1. As expected, the baseline neutrophil count, hemoglobin level, or platelet count was a risk factor for events at the grade 3 or 4 level. In addition, the baseline renal function was found to affect significantly the occurrence of severe neutropenia. Consequently, the estimated inci- 
Table 2. Identified risk factors and estimated odds ratios for key adverse events of S-1

\begin{tabular}{|c|c|c|c|c|c|}
\hline $\begin{array}{l}\text { Adverse events } \\
\text { (grade } 3-4)\end{array}$ & Identified risk factors & Catego & aseline) & Odds ratio & $P$ valve \\
\hline Neutropenia & $\begin{array}{l}\text { Neutrophil count } \\
\text { Creatinine clearance }^{a}\end{array}$ & $\begin{array}{l}\geq 2000 \\
\geq 80\end{array}$ & $\begin{array}{c}<2000 \\
50-79 \\
30-49 \\
<30\end{array}$ & $\begin{array}{l}3.99 \\
1.21 \\
1.79 \\
2.43\end{array}$ & $\begin{array}{r}<0.001 \\
0.238 \\
0.005 \\
0.107\end{array}$ \\
\hline Hemoglobin decrease & $\begin{array}{l}\text { Hemoglobin level } \\
\text { Irinotecan use }\end{array}$ & $\begin{array}{l}\geq 9.0 \\
\text { No }\end{array}$ & $\begin{array}{l}<9.0 \\
\text { Yes }\end{array}$ & $\begin{array}{l}5.05 \\
3.07\end{array}$ & $\begin{array}{r}<0.001 \\
0.003\end{array}$ \\
\hline Nausea/vomiting & $\begin{array}{l}\text { Baseline nausea/vomiting } \\
\text { ECOG performance status } \\
\text { Mytomicin use }^{\text {b }}\end{array}$ & $\begin{array}{c}\text { Absent } \\
0 \\
\\
\text { No }\end{array}$ & $\begin{array}{c}\text { Present } \\
1 \\
2 \\
3-4 \\
\text { Yes }\end{array}$ & $\begin{array}{l}3.59 \\
1.54 \\
1.86 \\
7.45 \\
2.28\end{array}$ & $\begin{array}{r}<0.001 \\
0.025 \\
0.029 \\
<0.001 \\
0.004\end{array}$ \\
\hline Anorexia & $\begin{array}{l}\text { Baseline anorexia } \\
\text { ECOG performance status }\end{array}$ & $\begin{array}{c}\text { Absent } \\
0\end{array}$ & $\begin{array}{c}\text { Present } \\
1 \\
2 \\
3-4\end{array}$ & $\begin{array}{l}3.62 \\
1.51 \\
1.35 \\
4.15\end{array}$ & $\begin{array}{r}<0.001 \\
<0.001 \\
0.117 \\
0.005\end{array}$ \\
\hline Hyperbilirubinemia & $\begin{array}{l}\text { Liver metastasis }^{c} \\
\text { Platelet count } \\
\text { Cisplatin use }^{\mathrm{b}}\end{array}$ & $\begin{array}{l}\text { Absent } \\
\geq 10^{5} \\
\text { No }\end{array}$ & $\begin{array}{l}\mathrm{H} 1 \\
\mathrm{H} 2 \\
\mathrm{H} 3 \\
<10^{5} \\
\text { Yes }\end{array}$ & $\begin{array}{l}0.57 \\
1.34 \\
2.44 \\
4.31 \\
1.60\end{array}$ & $\begin{array}{r}0.226 \\
0.446 \\
<0.001 \\
0.004 \\
0.007\end{array}$ \\
\hline Thrombocytopenia & ECOG performance status & $\geq 10^{5}$ & $\begin{array}{c}1 \\
2 \\
3-4 \\
<10^{5}\end{array}$ & $\begin{array}{l}1.77 \\
2.85 \\
-\mathrm{d} \\
7.85\end{array}$ & $\begin{array}{c}0.019 \\
0.002 \\
-\overline{<} \\
<0.001\end{array}$ \\
\hline Fatigue & Liver metastasis & Absent & $\begin{array}{c}\text { H1 } \\
\text { H2 } \\
\text { H3 } \\
\text { Present }\end{array}$ & $\begin{array}{l}1.10 \\
1.42 \\
1.69 \\
5.70\end{array}$ & $\begin{array}{r}0.720 \\
0.202 \\
0.001 \\
<0.001\end{array}$ \\
\hline
\end{tabular}

ECOG, Eastern Cooperative Oncology Group

Units: creatinine clearance $(\mathrm{ml} / \mathrm{min})$, neutrophil and platelet counts $\left(/ \mathrm{mm}^{3}\right)$, hemoglobin level $(\mathrm{g} / \mathrm{dl})$

${ }^{a}$ Calculated by the Cockcroft and Gault equation

${ }^{\mathrm{b}}$ Use history within 6 months prior to start of S-1 treatment

${ }^{\mathrm{c}} \mathrm{H} 1$, unilateral lobe metastasis; $\mathrm{H} 2$, bilateral lobe metastasis with a few scattered foci; H3, bilateral lobe metastasis with numerous foci

${ }^{\mathrm{d}}$ No estimation was obtained because of the number of cases

dence of neutropenia remained at only $5.0 \%$ for patients with a normal neutrophil count and a normal renal function at baseline, whereas it increased drastically up to $33.7 \%$ for patients whose status for these two features differed from normal. Other severe adverse events, including anorexia and fatigue, were also highly related to the baseline condition, which implies the importance of patient selection before commencing S-1 administration.

Nausea/vomiting (a key gastrointestinal adverse effect of fluoropyrimidine decreasing patients' quality of life), anorexia (one of the most frequent adverse events of S-1), and thrombocytopenia were influenced to a great extent by the baseline performance status (PS). Notably, patients with PS $=1$ were shown to have a statistically significant higher risk of nausea/vomiting, anorexia, or thrombocytopenia than those with PS $=0$ (nausea/vomiting: $\mathrm{OR}=1.54, P=0.025$; anorexia: $\mathrm{OR}$ $=1.51, P<0.001$; thrombocytopenia: OR $=1.77, P=$ $0.019)$.

Another result from our analysis to be taken into consideration when assessing the safety of S-1 is that the previous use of some chemotherapeutic drugs may be implicated in the experience of severe adverse events. The analysis suggested that use of some chemotherapeutic agents prior to the start of S-1 treatment might affect outcomes, such as nausea/vomiting, hemoglobin decrease, and hyperbilirubinemia. Although the possible mechanisms for the effects caused by these drugs are not clear, more caution is in order for the patients who having been treated with such drugs.

The current postmarketing survey was conducted under a well-organized scheme and provided us with an opportunity to evaluate not only reliable incidence rates 
Table 3. Estimated incidence probabilities of (a) neutropenia (b), nausea/vomiting, and (c) hyperbilirubinemia according to subgroups identified by risk factors

(a) Grade 3-4 neutropenia

\begin{tabular}{lcr}
\hline & \multicolumn{2}{c}{ Baseline neutrophil count $\left(/ \mathrm{mm}^{3}\right)$} \\
\cline { 2 - 3 } $\begin{array}{l}\text { Creatinine clearance } \\
(\mathrm{ml} / \mathrm{min})\end{array}$ & $\geq 2000$ & $<2000$ \\
\hline$\geq 80$ & $5.0 \%$ & $17.3 \%$ \\
$50-79$ & $6.0 \%$ & $20.2 \%$ \\
$30-49$ & $8.6 \%$ & $27.3 \%$ \\
$<30$ & $11.3 \%$ & $33.7 \%$ \\
\hline
\end{tabular}

${ }^{a}$ Calculated by the Cockcroft and Gault equation

(b) Grade 3-4 nausea/vomiting

\begin{tabular}{lcrr}
\hline \multirow{2}{*}{$\begin{array}{l}\text { ECOG performance } \\
\text { status }\end{array}$} & & \multicolumn{2}{c}{ Baseline nausea/vomiting } \\
\cline { 3 - 4 } & Mytomicin use $^{\mathrm{a}}$ & Absent & Present \\
\hline 0 & No & $1.5 \%$ & $5.1 \%$ \\
& Yes & $3.3 \%$ & $10.9 \%$ \\
& No & $2.3 \%$ & $7.6 \%$ \\
2 & Yes & $5.0 \%$ & $15.9 \%$ \\
& No & $2.7 \%$ & $18.1 \%$ \\
$3-4$ & Yes & $6.0 \%$ & $28.6 \%$ \\
& No & $10.0 \%$ & $47.8 \%$ \\
\hline
\end{tabular}

${ }^{\mathrm{a}}$ Use history within 6 months prior to start of S-1 treatment

(c) Grade 3-4 hyperbilirubinemia

\begin{tabular}{lccr}
\hline & & \multicolumn{2}{c}{ Baseline platelet count $\left(/ \mathrm{mm}^{3}\right)$} \\
\cline { 3 - 4 } Liver metastasis & Cisplatin use $^{\mathrm{a}}$ & $\geq 10^{5}$ & $<10^{5}$ \\
\hline Absent & No & $1.8 \%$ & $7.3 \%$ \\
& Yes & $2.9 \%$ & $11.2 \%$ \\
$\mathrm{H} 1$ & No & $0.1 \%$ & $4.3 \%$ \\
& Yes & $1.6 \%$ & $6.7 \%$ \\
$\mathrm{H} 2$ & No & $2.4 \%$ & $9.5 \%$ \\
& Yes & $3.8 \%$ & $14.4 \%$ \\
$\mathrm{H} 3$ & No & $4.3 \%$ & $16.1 \%$ \\
& Yes & $6.7 \%$ & $23.6 \%$ \\
\hline
\end{tabular}

${ }^{a}$ Use history within 6 months prior to start of S-1 treatment

but the risk factors for severe adverse outcomes. The survey has demonstrated the tolerable toxicity of S-1 among the nearly 4000 patients, affirming the results of the phase II studies and thus providing a sound basis for the safe use of S-1. Our analysis has effectively enabled the identification of patient subgroups potentially at higher risk with S-1 administration, thus is expected to be conducive to the drug's safer administration and to establish requirements for new therapy options. The insight gained from postmarketing surveys should help us understand many of the safety facets of chemotherapeutic agents as well as facilitate reevaluation of the results obtained in premarketing clinical trials. Active involvement in postmarketing surveys would contribute to facilitating safer administration of drugs.

\section{References}

1. Shirasaka T, Shimamato Y, Ohshimo H, Yamaguchi M, Kato T, Yonekura K, et al. Development of a novel form of an oral 5fluorouracil derivative (S-1) directed to the potentiation of the tumor selective cytotoxicity of 5 -fluorouracil by two biochemical modulators. Anticancer Drugs 1996;7:548-57.

2. Shirasaka T, Shimamoto Y, Fukushima M. Inhibition by oxonic acid of gastrointestinal toxicity of 5-fluorouracil without loss of its antitumor activity in rats. Cancer Res 1993;53:4004-9.

3. Sakata Y, Ohtsu A, Horikoshi N, Sugimachi K, Mitachi Y, Taguchi T. Late phase II study of novel oral fluoropyrimidine anticancer drug S-1 ( $1 \mathrm{M}$ tegafur- $0.4 \mathrm{M}$ gimestat- $1 \mathrm{M}$ otastat potassium) in advanced gastric cancer patients. Eur J Cancer 1998;34:1715-20.

4. Koizumi W, Kurihara M, Nakano S, Hasegawa K. Phase II study of S-1, a novel oral derivative of 5-fluorouracil, in advanced gastric cancer: for the S-1 Cooperative Gastric Cancer Study Group. Oncology 2000;58:191-7. 
5. Furuse J, Okusaka T, Funakoshi A, Boku N, Yamao K, Ohkawa S, et al. A phase II study of S-1 in patients with metastatic pancreatic cancer. Proc Am Soc Clin Oncol 2005;23:abstract 4104.

6. Shirao K, Ohtsu A, Takada H, Mitachi Y, Hirakawa K, Horikoshi $\mathrm{N}$, et al. Phase II study of oral S-1 for treatment of metastatic colorectal carcinoma. Cancer 2004;100:2355-61.

7. Saek T, Takashima S, Sano M, Horikoshi N, Miura S, Shimizu S, et al. A phase II study of S-1 in patients with metastatic breast cancer - a Japanese trial by the S-1 Cooperative Study Group, Breast Cancer Working Group. Breast Cancer 2004;11:194-202.

8. Kawahara M, Furuse K, Segawa Y, Yoshimori K, Matsui K, Kudoh S, et al. Phase II study of S-1, a novel oral fluorouracil, in advanced non-small-cell lung cancer. $\mathrm{Br}$ J Cancer 2001;85: 939-43.

9. Inuyama Y, Kida A, Tsukuda M, Kohno N, Satake B. Late phase II study of S-1 in patients with advanced head and neck cancer. Jpn J Cancer Chemother 2001;28:1381-90.

10. Ohtsu A, Baba H, Sakata Y, Mitachi Y, Horikoshi N, Sugimachi $\mathrm{K}$, et al. Phase II study of S-1, a novel oral fluoropyrimidine derivative, in patients with metastatic colorectal carcinoma; S-1 Cooperative Colorectal Carcinoma Study Group. Br J Cancer 2000;83:141-5.
11. Nagashima F, Ohtsu A, Yoshida S, Ito K. Japanese nationwide post-marketing survey of S-1 in patients with advanced gastric cancer. Gastric Cancer 2005;8:6-11.

12. Grading of toxicity. In: Wittes RE, editor. Manual of oncology therapeutics. Philadelphia: Lippincott; 1991. p. 445-8.

13. Japan Society of Clinical Oncology. Adverse drug reaction criteria of the Japan Society of Clinical Oncology. Int J Clin Oncol 1997;2:177-9.

14. Hosmer D, Lemeshow S. Applied logistic regression. 2nd edition. New York: Wiley; 2000.

15. Cockcroft DW, Gault MH. Prediction of creatinine clearance from serum creatinine. Nephron 1976;16:31-41.

16. Cassidy J, Twelves C, Van Cutsem E, Hoff P, Bajetta E, Boyer $\mathrm{M}$, et al. First-line oral capecitabine therapy in metastatic colorectal cancer: a favorable safety profile compared with intravenous 5-fluorouracil/leucovorin. Ann Oncol 2002;13:5669-75.

17. Kane RC, Farrell AT, Saber H, Tang S, Williams G, Jee JM, et al. Sorafenib for the treatment of advanced renal cell carcinoma. Clin Cancer Res 2006;12:7271-8.

18. Taguchi T, Inuyama Y, Kanamaru R, Hasegawa K, Akazawa S, Niitani H, et al. Phase I study of S-1; S-1 Study Group. Jpn J Cancer Chemother 1997;24:2253-64. 